\title{
Characterization of Aluminum Alloy-Based Nanocomposites Produced by the Addition of AL-TI5-B1 to the Matrix Melt
}

\author{
${ }^{1}$ Hashem F. El-Labban, ${ }^{2}$ M. Abdelaziz and ${ }^{3}$ Essam R.I. Mahmoud \\ ${ }^{1}$ Department of Production Engineering, Alexandria University, Alex, Egypt \\ ${ }^{2}$ Composite Material Lab., Department of Advanced Materials, CMRDI, Cairo, Egypt \\ ${ }^{3}$ Welding and NDT Lab., Department of Manufacturing Technology, CMRDI, Cairo, Egypt
}

Received 2013-12-23; Revised 2013-12-26; Accepted 2014-01-09

\begin{abstract}
The present study is an attempt to produce aluminum matrix nanocomposites using a certain aluminum alloy (which its melt has high fluidity) as a matrix material and reinforced with hard and stable fine (nano-sized) precipitates. Therefore, Al-Ti5-B1 master alloy and Al-Si alloy of high silicon content were proposed for preparation of such nanocomposites. Three nanocomposites were prepared by adding AlTi5-B1 of three different percentages $(1,2$ and $3 \mathrm{wt} . \%)$ to the melt of aluminum alloy at $710^{\circ} \mathrm{C}$ for a holding time of $10 \mathrm{~min}$ and application of mechanical stirring at this temperature. Finally, the treated melt was squeeze cast. The microstructures were investigated using optical and scanning electron microscopes. Phases and different constituents were analyzed with the aid of EDX and XRD analyzers. The addition of Al-Ti5-B1 master alloy with any percentages (even $1 \mathrm{wt}$ \%) to the melt of aluminum alloy, led to remarkable decrease of the matrix grain size. Moreover, many fine precipitates were detected within the $\mathrm{Al}-\mathrm{Si}$ matrix such as $\mathrm{TiAl}_{3}$ phase in the form of flaky and blocky morphology and $\mathrm{TiB}_{2}$ phase in the nano-sized particles. These precipitates act as heterogeneous sites for nucleation during solidification. The addition of Al-Ti5-B1 master alloy to the Al-Si base metal led to remarkable increase in the average hardness. As the added percentage of Al-Ti5-B1 master alloy is increased, the average hardness value is increased. The average hardness of addition of $3 \mathrm{wt}$ \% Al-Ti5-B1 master alloy reached $130 \mathrm{HV}$, which was almost twice as high as the hardness of the Al-Si base metal.
\end{abstract}

Keywords: Aluminium Grain Refinement, Al-Ti5-B1 Master Alloy, $\mathrm{TiB}_{2}$ Particles, $\mathrm{TiAl}_{3}$ Intermetallic Compounds, Aluminium Matrix Nanocomposites, Hardness, Wear Resistance

\section{INTRODUCTION}

For a long period, aluminum alloys were some of the most widely used materials as the matrix of metal matrix composites MMCs, both in research and development and in industrial applications. This is mainly due to the low density of aluminum alloys (the first requirement in most application). Moreover, they are inexpensive in comparison with other low density alloys (such as $\mathrm{Mg}$ or Ti) (Feng and Froyen, 2000). Nowadays, Aluminum Metal Matrix Composites (AMMCs) are one of the advanced engineering materials that have been Corresponding Author: Hashem F. El-Labban, Department of Production Engineering, Alexandria University, Alex, Egypt

developed for weight critical applications in the aerospace, defense, marine and more recently in the automotive and transport industries due to their excellent combination of high specific strength and superior wear resistance. In the automobile sector, AMMCs are used for making various components such as pistons, cylinder heads, connecting rods, where the tribological properties of the materials are very important (Sajjadi et al., 2012; Yadav et al., 2011; Storjohann et al., 2005). MMCs with uniform dispersion particles in the range of $10 \mathrm{~nm}-1 \mu \mathrm{m}$ are termed "Metal Matrix Nano-Composites" (MMNCs). These nano- 
composites exhibit more outstanding properties over ordinary MMCs and are assumed to overcome the shortcoming of MMCs such as poor ductility, low fracture toughness and machinability (Sathyabalan et al., 2009; Srinivasan et al., 2012).

The widely used particle for reinforcing $\mathrm{Al}$ alloys is $\mathrm{SiC}$. Besides its low density and low cost, $\mathrm{SiC}$ enhances an increase in the Young's modulus, hardness and tensile strength. However, these composites suffer from a great loss in ductility and toughness due to the undesirable reactions between $\mathrm{SiC}$ particles and aluminum, yielding $\mathrm{Al}_{4} \mathrm{C}_{3}$ interfacial product, which limits their applications to a certain extent (Mahmoud et al., 2008). On the other hand, Titanium diboride $\left(\mathrm{TiB}_{2}\right)$ has distinct advantages over $\mathrm{SiC}$ because of its inertness to aluminum matrix (Shackelford and Alexander, 2001). In other words, formation of brittle intermetallic products at the interface between the reinforcement and matrix can be avoided using the $\mathrm{TiB}_{2}$ particles. Moreover, $\mathrm{TiB}_{2}$ particles exhibit high elastic modulus and hardness, high melting point and electrical conductivity as well as good thermal stability. On the other hand, there was a great limitation on the amount of $\mathrm{TiB}_{2}$ particles added to the matrix due to the higher viscosity of the resultant MMCs. Accordingly; several studies have been conducted to syntheses the in situ $\mathrm{TiB}_{2}$ particulate reinforced Al-based composites with enhanced mechanical properties (Salvador et al., 2003; Tjong and Huo, 2009; Boopathi et al., 2013; Sivaprasada et al., 2008).

Moreover, the titanium aluminides; $\mathrm{TiAl}_{3}$ and $\mathrm{TiAl}$, have been considered one of most important reinforcement candidates due to their low density, excellent mechanical properties, especially at high temperatures and high wear resistance (Adamiak et al., 2004; Sathyabalan et al., 2009). These unique properties of $\mathrm{Al}$ based MMCs reinforced with titanium aluminides make them a good candidate to substitute traditional high temperature alloys, such as nickel super alloys, in the aerospace industry, especially in turbine elements (Salvador et al., 2003).

Regarding the aluminum matrix, grain refinement is a common way to increase both strength and toughness of the material at ambient temperatures (Wang et al., 2004). Fine grain structure can be produced by various methods: Using grain refiners, rapid solidification, mechanical milling/alloying of powder metals and severe plastic deformation (SPD).

It is expected that addition of Al-Ti5-B1 master alloy to the melted aluminum during casting can achieve almost all the previous advantages by one step. AlTi5-B1 master alloy is one of the main grain refiners (Yi et al., 2006). In situ aluminum aluminides $\left(\mathrm{Al}_{3} \mathrm{Ti}\right)$ and $\mathrm{TiB}_{2}$ particles can be formed during solidification by the reactions between $\mathrm{Al}$ and $\mathrm{Ti}$ and between $\mathrm{Ti}$ and B elements (Nagli et al., 2008). The present study has been undertaken to present the feasibility of adding AlTi5-B1 master alloy to the melted Al-Si base alloy and to reveal the grain refinement and any resultant in situ reactions formed during solidification.

\section{MATERIALS AND METHODS}

In this study, Al-Si alloy was used as a base material. The chemical composition of this base material is shown in Table 1. Al-Ti5-B1 master alloy was added in different percentages (1, 2 and 3 wt. \%) to the melted Al$\mathrm{Si}$ alloy at $710^{\circ} \mathrm{C}$, for a holding time of $10 \mathrm{~min}$. Mechanical stirring was applied at this temperature and then squeeze casted. The microstructures of the matrix material (Al-Si alloy) and the resultant intermetallics were investigated using optical and scanning electron microscopes equipped with EDX analyzer. The resulted microstructures were analyzed by X-Ray Diffractometer, (XRD) to identify experimentally the new phases that were in situ formed inside the Al-Si matrix. The microhardness of the product was also measured with Vickers hardness tester at $200 \mathrm{~g}$ load for $15 \mathrm{~s}$.

\section{RESULTS}

\subsection{Microstructure Analysis}

Macroscopic appearance of the Al-Si base metal without any addition together with that produced after addition of Al-Ti5-B1 master alloy with different concentrations, are shown in Fig. 1. Generally, there was a great reduction in $\alpha$-Al grain size after the addition of Al-Ti5-B1 master alloy to the Al-Si base metal (compare Fig. 1a-c. On the other hand, the addition of different concentrations of Al-Ti5-B1master alloy to the Al-Si base metal has almost no significant changes in the grain size (compare Fig. 1b with Fig. 1c). Figure 2 and 3 show the scanning electron micrographs for the microstructures of $\mathrm{Al}-\mathrm{Si}$ base metal treated by the addition of Al-Ti5-B1 master alloy with concentration of 1 and 3\%, respectively. At lower magnifications (Fig. 2a and 3a), both microstructures show fine dendritic eutectic morphology structure inside $\alpha$-Al grains.

Table 1. Chemical composition of the base aluminum alloy; (wt.\%)

\begin{tabular}{lllllllllll}
\hline $\mathrm{Al}$ & $\mathrm{V}$ & $\mathrm{Pb}$ & $\mathrm{Cr}$ & $\mathrm{Ti}$ & $\mathrm{Ni}$ & $\mathrm{Mg}$ & $\mathrm{Mn}$ & $\mathrm{Cu}$ & $\mathrm{Fe}$ & $\mathrm{Si}$ \\
\hline Bal. & 0.02 & 0.01 & 0.02 & 0.02 & 0.13 & 0.51 & 0.40 & 2.06 & 0.41 & 7.22 \\
\hline
\end{tabular}



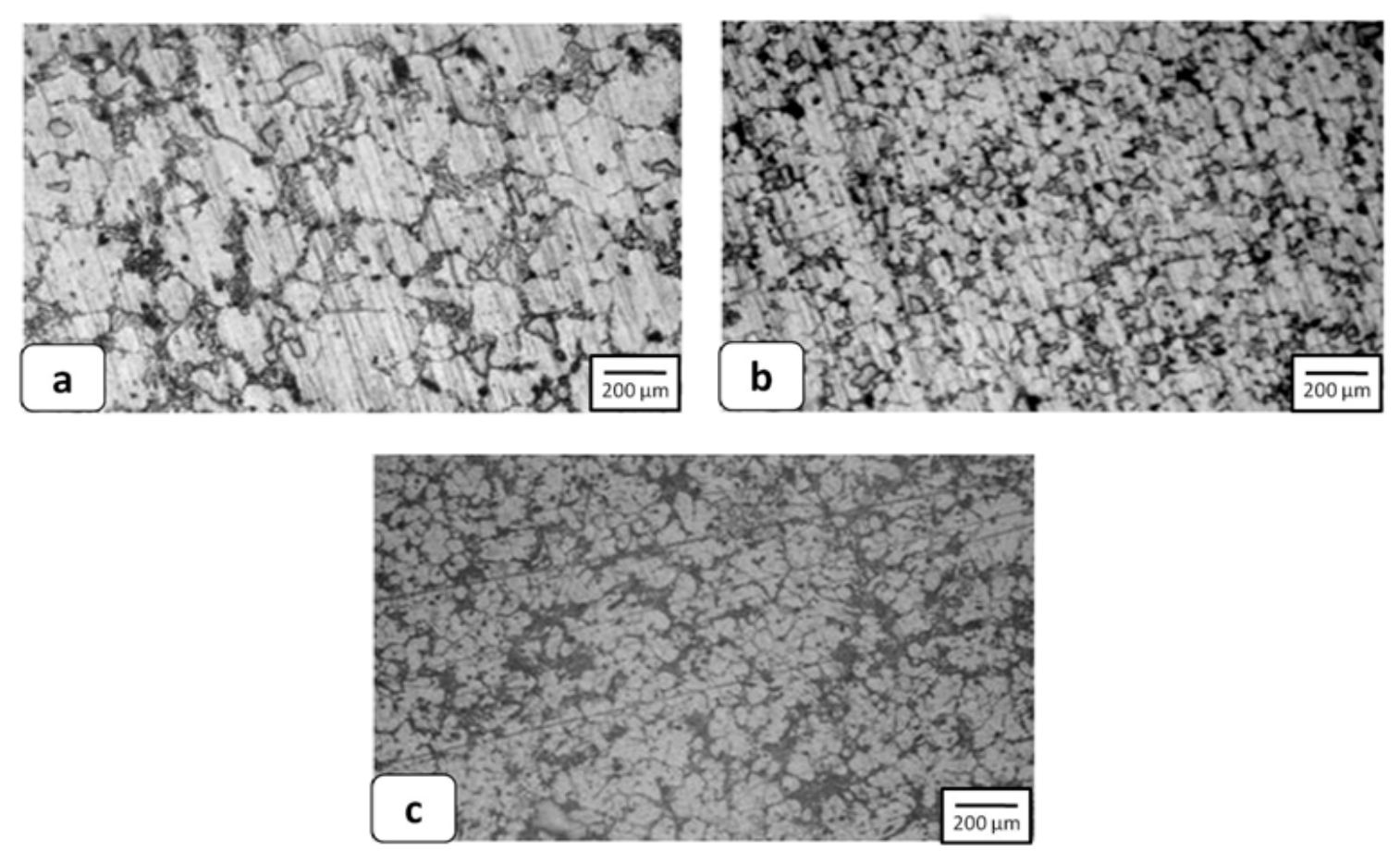

Fig. 1. Optical microscopic appearances of: (a) Al-Si base metal without any addition, (b) and (c) base metal with addition of 1 and $3 \%$ Al-Ti5-B1 master alloy, respectively
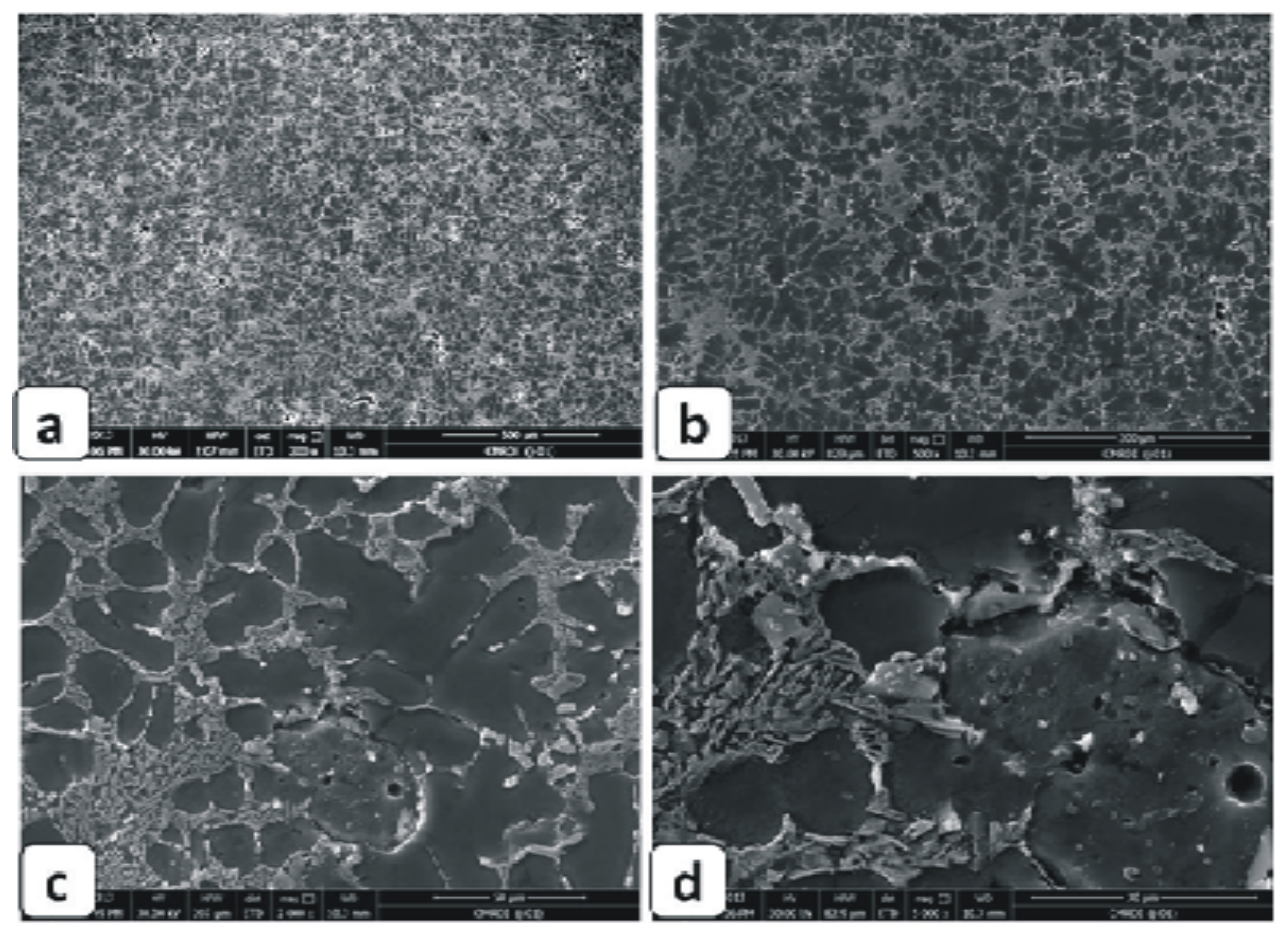

Fig. 2. Different magnified SEM micrographs of Al-Si base metal with addition of 1\% Al-Ti5-B1 master alloy 
Hashem F. El-Labban et al. / American Journal of Nanotechnology 4 (1): 8-15, 2013
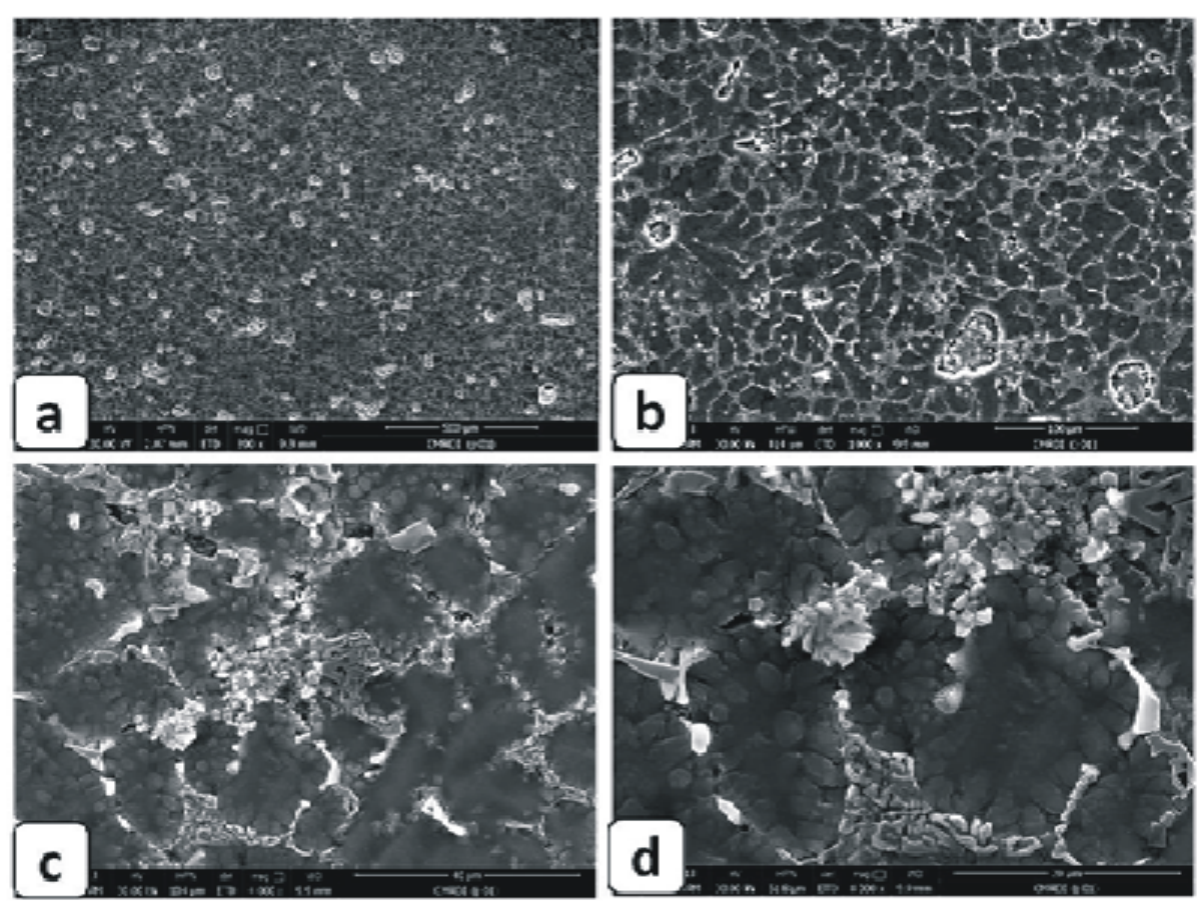

Fig. 3. Different magnified SEM micrographs of Al-Si base metal with addition of 3\% Al-Ti5-B1 master alloy

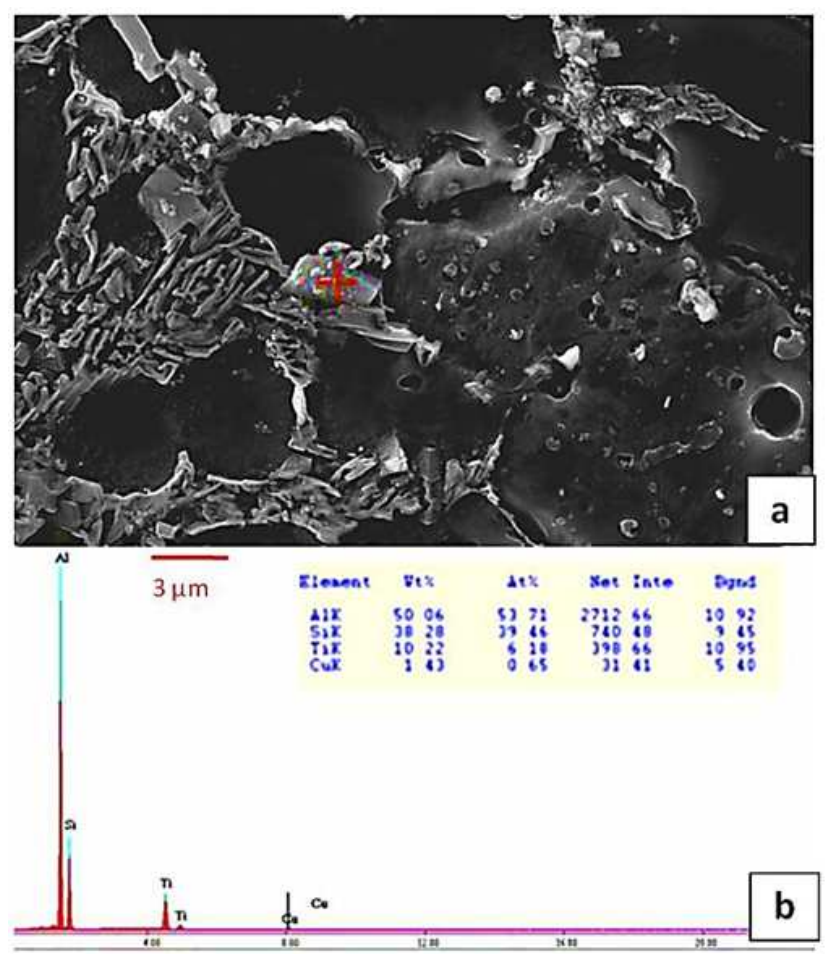

Fig. 4. EDS spectra of the cross mark in SEM micrographs of Al-Si base metal with addition of 1\% Al-Ti5-B1 master alloy, indicating that it is $\mathrm{TiAl}_{3}$ intermetallics 
Hashem F. El-Labban et al. / American Journal of Nanotechnology 4 (1): 8-15, 2013

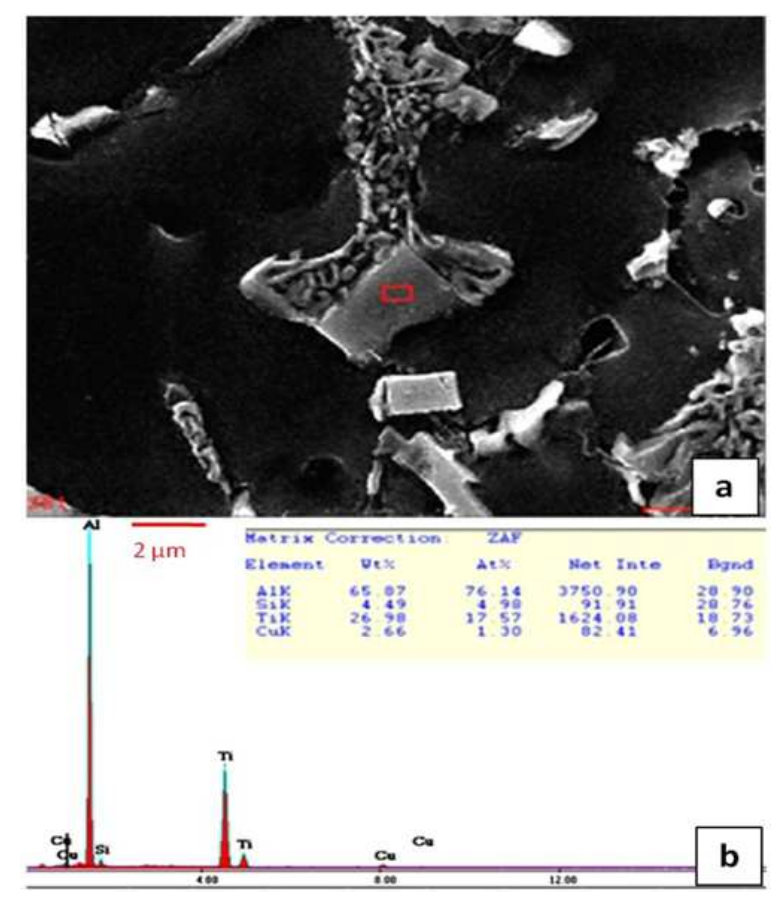

Fig. 5. EDS spectra of the red mark in SEM micrographs of Al-Si base metal with addition of 3\% Al-Ti5-B1 master alloy, indicating that it is TiAl3 intermetallics

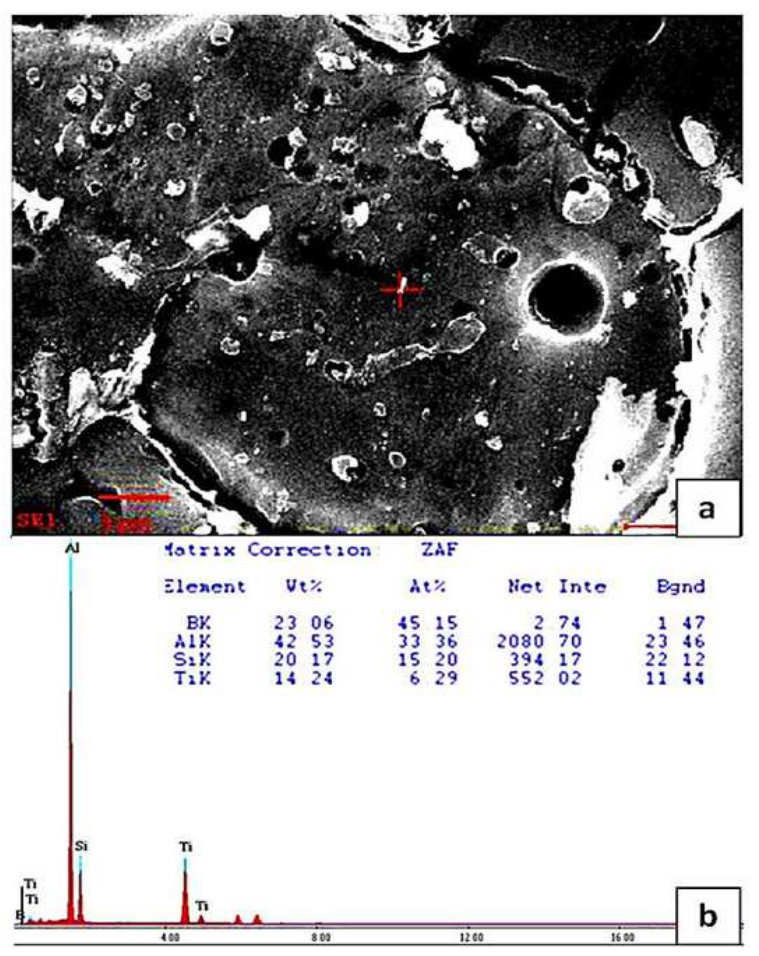

Fig. 6. EDS spectra of the cross mark in a grain center of Al-Si base metal with addition of 1\% Al-Ti5-B1 master alloy, indicating that it is $\mathrm{TiB}_{2}$ particles 


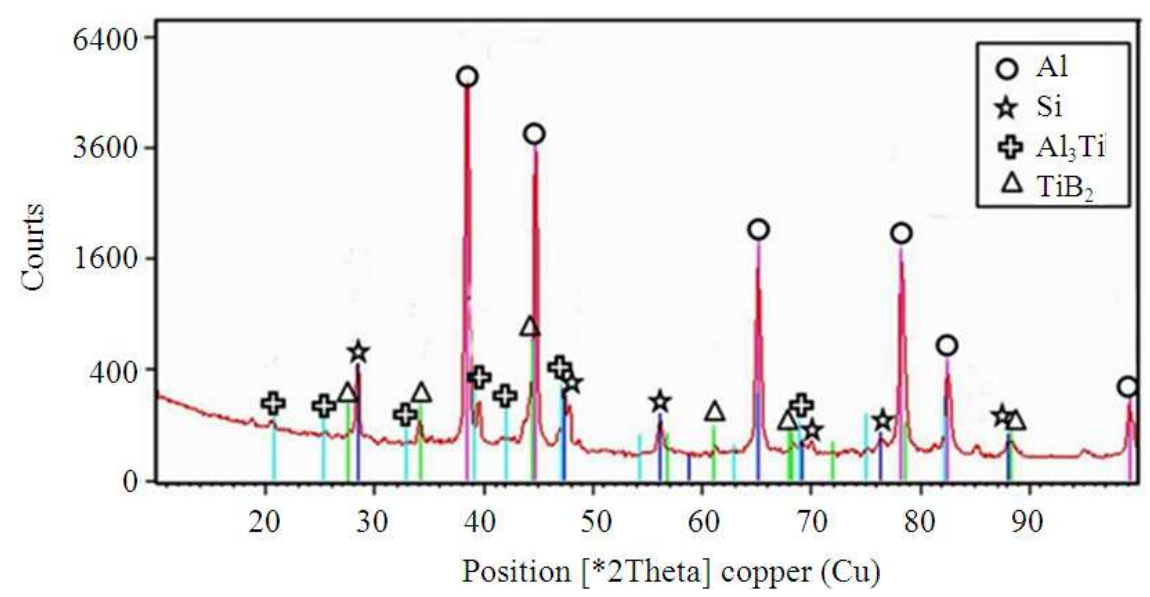

Fig. 7. XRD pattern of the sample that had addition of 3\% Al-Ti5-B1 master alloy

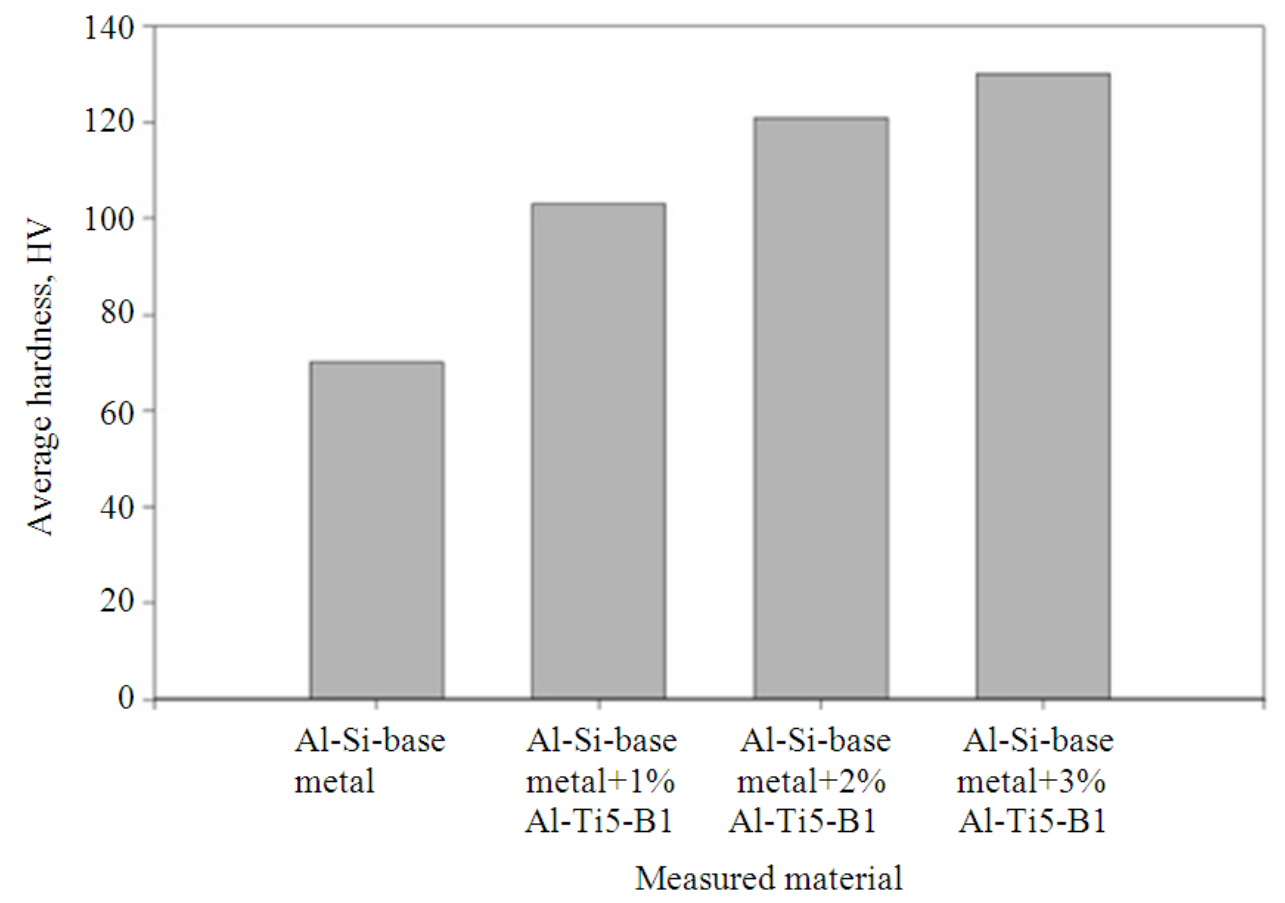

Fig. 8. Average hardness of Al-Si base metal and with addition of 1\% Al-Ti5-B1 master alloy with different concentration

These dendrite structures are formed from the Si content of the base metal. Moreover, many precipitates are detected inside the Al matrix. At higher magnifications, these precipitates are appeared in the form of relatively large flakes and blocks in the Al matrix, especially at the grain boundaries, as clearly shown in Fig. 2c and 3c. By comparing SEM micrographs of Fig. 2 and 3 , the percentage of precipitated $\mathrm{TiAl}_{3}$ phase is greater in case of addition 3\% Al-Ti5-B1 master alloy (Fig. 3) than that of addition of $1 \%$ (Fig. 2). With the aid of the EDX analysis, these flaky and blocky morphology precipitates are most probably $\mathrm{TiAl}_{3}$ intermetallics (Fig. 4 and 5). At the grain center, both $\mathrm{TiB}_{2}$ and $\mathrm{TiAl}_{3}$ phases can be found as shown in Fig. 6. The XRD pattern of the sample that had addition of 3\% Al-Ti5-B1 master alloy is shown in Fig. 7. It was clear that there were $\mathrm{TiB}_{2}$ and 
$\mathrm{TiAl}_{3}$ phases in addition to that of the base metal; $\mathrm{Al}$ and $\mathrm{Si}$, which confirms the microstructure analysis.

\subsection{Hardness Measurements}

Microhardness of the base material and the prepared nanocomposites was measured using microhardness tester and the measured values are presented in Fig. 8. It is clear that the addition of Al-Ti5-B1 master alloy to the Al-Si base metal led to remarkable increase in the average hardness. As the added percentage of Al-Ti5-B1 master alloy is increased, the average hardness value is increased. The average hardness of addition of 3\% AlTi5-B1 master alloy reached $130 \mathrm{HV}$, which was almost twice as high as the hardness of the Al-Si base metal.

\section{DISCUSSION}

Coarse columnar $\alpha-\mathrm{Al}$ dendritic grains are clearly revealed in the microstructure of the untreated alloy. With the addition of $1 \mathrm{wt}$ \% of Al-Ti5-B1 master alloy, the coarse dendritic structure was transformed into another one of fine and equiaxed grains. The results showed thatthe increase in percentages of Al-Ti5-B1 master alloy ( 2 and $3 \mathrm{wt}$. \%) has no significant effect on the grain refinement. This is may be due to that the grain refinement needs a very small amount of Al-Ti5-B1 master alloy (normally $0.2 \mathrm{wt}$. \%). The extra amount will be precipitated as reinforcing particles. These particles are fine $\mathrm{TiB}_{2}$ and $\mathrm{TiAl}_{3}$ precipitates. They can be considered as heterogeneous sites for nucleation during solidification and also as obstacles for grain growth, which lead to grain refinement. In addition to the grain refinement, the dendrite arm spacing of microstructure produced by addition of 3\% Al-Ti5-B1 master alloy is finer than that of addition of $1 \%$ (Fig. 2a and Fig. 3a). This can be attributed to the higher percentage of precipitated $\mathrm{TiAl}_{3}$ phase in case of 3\% Al-Ti5-B1 master alloy addition (Fig. 3). Moreover, many other fine (nano-sized) precipitates are appeared inside the grains (almost in the grain center). In addition to the grain refining effect of these precipitates, they shorten the eutectic dendrite arms. No normal long needle eutectic silicon is appeared. This means that the formation of in-situ $\mathrm{TiB}_{2}$ and $\mathrm{TiAl}_{3}$ particles not only refine the matrix grains but also change the eutectic structure into short forms.

As well known, the microstructure features affect the hardness of the material. It was noticed that, the grain refinement is accompanied by an increase in the hardness. In addition, the reinforcing particles strengthen the material. So, in the present investigation, the increment in hardness values by addition of Al-Ti5-B1 master alloy to the Al-Si base metal can be mainly attributed to two reasons. Firstly, the grain refinement of the base metal that can greatly share in this increment. Secondly, the formation of insitu fineTiB ${ }_{2}$ and $\mathrm{TiAl}_{3}$ precipitates inside the $\mathrm{Al}$ matrix, which act as reinforcing particles. These fine precipitates are very hard, very stable even at high temperature and they can be considered as reinforcement candidates, as reported by other investigators (Salvador et al., 2003). As a final conclusion, the presence of $\mathrm{TiB}_{2}$ and $\mathrm{TiAl}_{3}$ with high percentages can be considered as grain refining and reinforcing particles.

\section{CONCLUSION}

In this study, we presented a detailed study on the effect resulted from addition of Al-Ti5-B1 master alloy in different percentages (1,2 and $3 \mathrm{wt}$. \%) to the melt of considered Al-Si base metal at $710^{\circ} \mathrm{C}$ for a holding time of $10 \mathrm{~min}$ and application of mechanical stirring and squeeze casting. The results obtained can be summarized as follows:

- The addition of Al-Ti5-B1 master alloy with any percentages (even 1 wt. \%) to the melt of investigated aluminum alloy, led to remarkable decrease of the matrix grain size

- The addition of Al-Ti5-B1 master alloy to the Al-Si alloy led to fine eutectic dendrites at the boundaries of $\alpha$-Al grains

- The amount of added Al-Ti5-B1 master alloy to the Al-Si base metal had much less significant effect on the matrix grain size

- Many fine precipitates were detected within the AlSi matrix such as $\mathrm{TiAl}_{3}$ phase in the form of flaky and blocky morphology and $\mathrm{TiB}_{2}$ phase in the nanosized particles

- Addition of Al-Ti5-B1 master alloy to the Al-Si alloy had remarkable improvements in hardness. The hardness was increased to about $130 \mathrm{HV}$ for addition of 3\% Al-Ti5-B1 master alloy compared with about $70 \mathrm{HV}$ of the Al-Si base metal

\section{REFERENCES}

Adamiak, M., J.B. Fogagnolo, E.M. Ruiz-Navas, L.A. Dobrzaski and J.M. Torralba, 2004. Mechanically milled AA6061/( $\left.\mathrm{Ti}_{3} \mathrm{Al}\right)_{\mathrm{P}} \mathrm{MMC}$ reinforced with intermetallics-the structure and properties. J. Mater. Process. Technol., 155-156: 2002-2006. DOI: 10.1016/j.jmatprotec.2004.04.202 
Boopathi, M.M., K.P. Arulshri and N. Iyandurai, 2013. Evaluation of mechanical properties of aluminium alloy 2024 reinforced with silicon carbide and fly ash hybrid metal matrix composites. Am. J. Applied Sci., $\quad$ 10: 219-229. DOI: 10.3844/ajassp.2013.219.229

Feng, C.F. and L. Froyen, 2000. Microstructures of in situ $\mathrm{Al} / \mathrm{TiB}_{2}$ MMCs prepared by a casting route. J. Mater. Sci., 35: 837-850. DOI: 10.1023/A:1004729920354

Mahmoud, E.R.I., K. Ikeuchi and M. Takahashi, 2008. Fabrication of $\mathrm{SiC}$ particle reinforced composite on aluminium surface by friction stir processing. J. Sci. Technol. Weld. Join., 13: 607-618. DOI: 10.1179/136217108X333327

Nagli, I., A. Smolej and M. Doberek, 2008. Remelting of aluminium with the addition of AlTi5B1 and AlTi3C0,15 grain refiners. Metalurgija, 47: 115118.

Sajjadi, S.A., H.R. Ezatpour and M. TorabiParizi, 2012. Comparison of microstructure and mechanical properties of $\mathrm{A} 356$ aluminum alloy/ $\mathrm{Al}_{2} \mathrm{O}_{3}$ composites fabricated by stir and compo-casting processes. Mater. Design, 34: 106-111. DOI: 10.1016/j.matdes.2011.07.037

Salvador, M.D., V. Amigo, N. Martinez and D.J. Busquets, 2003. Microstructure and mechanical behaviour of Al-Si-Mg alloys reinforced with Ti-Al intermetallics. J. Mater. Process. Technol., 143-144: 605-611. DOI: 10.1016/S0924-0136(03)00440-0

Sathyabalan, P., V. Selladurai and P. Sakthivel, 2009. ANN based prediction of effect of reinforcements on abrasive wear loss and hardness in a hybrid MMC. Am. J. Eng. Applied Sci., 2: 50-53. DOI: 10.3844/ajeassp.2009.50.53
Shackelford, J.F. and W. Alexander, 2001. CRC Materials Science and Engineering Handbook. 3rd Edn., CRC Press, Boca Raton, ISBN-10: 0849326966, pp: 1949.

Sivaprasada, K., S.P. KumareshBabua and S. Natarajana, 2008. Study on abrasive and erosive wear behaviour of $\mathrm{Al} 6063 / \mathrm{TiB}_{2}$ in situ composites. Mater. Sci. Eng. A, 498: 495-500. DOI: 10.1016/j.msea.2008.09.003

Srinivasan, A., R.M. Arunachalam, S. Ramesh and J.S. Senthilkumaar, 2012. Machining performance study on metal matrix composites-a response surface methodology approach. Am. J. Applied Sci., 9: 478483. DOI: 10.3844/ajassp.2012.478.483

Storjohann, D., O.M. Barabash, S.A. David, P.S. Sklad and E. E. Bloom et al., 2005. Fusion and friction stir welding of aluminum-metal-matrix composites. Metall. Mater. Trans. A, 36A: 3237-3247. DOI: 10.1007/s11661-005-0093-4

Tjong, S.C. and H.W. Huo, 2009. Corrosion protection of in situ al-based composite by cerium conversion treatment. J. Mater. Eng. Perform., 18: 88-94. DOI: 10.1007/s1 1665-008-9264-y

Wang, X., A. Jha and R. Brydson, 2004. In situ fabrication of Al3Ti particle reinforced aluminium alloy metal-matrix composites. Mater. Sci. Eng. A, 364: 339-345. DOI: 10.1016/j.msea.2003.08.049

Yadav, R.K., N. Hasan and A. Yadav, 2011. Studies on mechanical properties of al-based cast composites. Int. J. Comput. Sci. Manage. Stud., 11: 104-109.

Yi, H., H. Man, Y. Zhang, X. Li and H. Wang, 2006. Effective elastic moduli of Al-Si composites reinforced in situ with $\mathrm{TiB}_{2}$ particles. Scripta Mater., 54: 1093-1097. DOI: 10.1016/j.scriptamat.2005.11.070 